\title{
Aspectos básicos de tomografia computadorizada e ressonância magnética
}

\author{
Edson Amaro Júnior ${ }^{a}$ e Helio Yamashitab
}

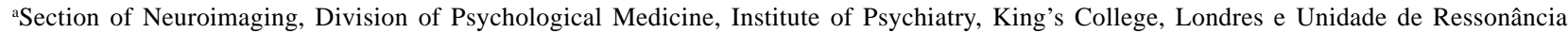
Magnética, Instituto de Radiologia (InRad), Hospital das Clínicas, Faculdade de Medicina, Universidade de São Paulo. 'bepartamento de Medicina por Imagem, Universidade Federal de São Paulo/Escola Paulista de Medicina
\end{abstract}

\section{Introdução}

A psiquiatria tem se beneficiado dos avanços tecnológicos das técnicas de neuroimagem nas duas ultimas décadas. Diversas pesquisas têm sido desenvolvidas. O presente artigo visa esclarecer aspectos metodológicos básicos em neuroimagem estrutural e funcional em tomografia computadorizada (TC) e ressonância magnética (RM).

\section{Tomografia computadorizada}

Essa técnica, que se baseia em raios-X, foi utilizada para aplicações clínicas ainda no início da década de 70, uma vez que torna possível examinar o encéfalo e, com maior clareza, os limites do sistema ventricular e as partes ósseas do crânio. $\mathrm{O}$ aparelho consiste em uma fonte de raios-X que é acionada ao mesmo tempo em que realiza um movimento circular ao redor da cabeça do paciente, emitindo um feixe de raios-X em forma de leque. No lado oposto a essa fonte, está localizada uma série de detectores que transformam a radiação em um sinal elétrico que é convertido em imagem digital. Dessa forma, as imagens correspondem a secções ("fatias") do crânio. A intensidade (brilho) reflete a absorção dos raios- $X$ e pode ser medida em uma escala (unidades Hounsfield).

Recentemente, com a evolução tecnológica, é possível adquirir imagens rapidamente através da técnica de varredura espiral (ou helicoidal). Essa inovação permite realizar o exame em aproximadamente três minutos (quando o presente artigo foi escrito). Torna possível também a angiografia por TC (angioTC) e outros procedimentos que se beneficiem de dados volumétricos. Isto facilita o exame de pacientes agitados.

Apesar dos avanços, ainda é limitada a capacidade de diferenciar entre substância branca e cinzenta, notadamente na região do cerebelo e núcleos da base. A grande deficiência é vista nas doenças desmielinizantes ou em algumas lesões neoplásicas infiltrativas e em transtornos psiquiátricos. A única indicação para esse exame em psiquiatria é a pesquisa de diagnósticos diferenciais como neoplasias e processos inflamatórios, em situações em que o acesso à RM é limitado.

\section{Ressonância magnética}

Algumas pessoas ainda utilizam o nome "ressonância magnética nuclear". O termo "nuclear" não é o mais correto, uma vez que causa confusão com radioatividade e não há radiação ionizante nesse método. A técnica fundamenta-se em três etapas: alinhamento, excitação e detecção de radiofreqüência. $\mathrm{O}$ alinhamento se refere à propriedade magnética de núcleos de alguns átomos, que tendem a se orientar paralelamente a um campo magnético (como uma bússola em relação ao campo magnético da terra). Por razões físicas e pela abundância, o núcleo de hidrogênio (próton) é o elemento utilizado para produzir imagens de seres biológicos (leia-se, nós). Assim, para que esses átomos sejam orientados numa certa direção, é necessário um campo magnético intenso - habitualmente cerca de 1,5 Teslas (30 mil vezes mais intenso que o campo magnético da terra). Entendida essa etapa, é possível associar o nome "magnética" e o antigo "nuclear". Falta entender "ressonância".

A etapa seguinte é a excitação. Sabe-se que cada núcleo de hidrogênio "vibra" numa determinada freqüência proporcional ao campo magnético em que está localizado. Assim, em 1,5 T, o hidrogênio tem freqüência de $63,8 \mathrm{MHz}$. O aparelho emite então uma onda eletromagnética nessa mesma freqüência. Existe uma transferência de energia da onda emitida pelo equipamento para os átomos de hidrogênio, fenômeno conhecido como ressonância.

Já temos agora o nome completo dessa técnica, mas falta informação de como são produzidas as imagens. Esta é a terceira etapa: detecção de radiofreqüência. Quando os núcleos de hidrogênio receberam a energia, tornaram-se instáveis. Ao retornar ao estado habitual, eles emitem ondas eletromagnéticas na mesma frequiência $(63,8 \mathrm{MHz}$ - faixa de ondas de rádio). Então o equipamento detecta essas ondas e determina a posição no espaço e a intensidade da energia. Essa intensidade é mostrada como "brilho" na imagem, sendo utilizada a nomenclatura "intensidade de sinal".

Dependendo da forma e do tempo em que excitamos os átomos, as imagens poderão ser mais sensíveis a diferentes propriedades dos tecidos (Figura 1). Por exemplo, temos as imagens T2, nas quais líquidos (liquor), desmielinização e áreas de edema no tecido cerebral se mostram mais claros - alto sinal. Nas imagens T1, a substância branca é mais clara que a cinzenta e áreas com alto conteúdo protéico e tecido adiposo em geral tem maior sinal - mais claras. ${ }^{1}$

As imagens de RM têm maior capacidade de demonstrar 
diferentes estruturas no cérebro e têm facilidade em demonstrar mínimas alterações na maioria das doenças. As alterações morfológicas são mais facilmente avaliadas do que na TC, bem como há maior sensibilidade para doenças desmielinizantes e processos infiltrativos. É também possível avaliar estruturas como hipocampos, núcleos da base e cerebelo (o qual é de difícil avaliação na TC) - em alguns casos necessárias para pesquisa de transtornos mentais. ${ }^{2}$

O aparelho é na verdade um túnel com cerca de 1,5 a 2,5 metros de comprimento e produz um ruído durante a emissão das ondas de radiofreqüência e procedimento de localização do sinal. Esse ambiente é limitante para claustrofobos, contraindicado para pacientes com marca-passo e "clips" de aneurismas (há outras contra-indicações formais).

\section{Ressonância magnética funcional}

A técnica de ressonância magnética funcional - RMf - é semelhante a um exame clínico dessa modalidade. As diferenças principais se devem à particularidade de se obter informações relativas à determinada função cerebral. Neste sentido, é necessário que haja uma forma controlada para executar essa função, por exemplo, fluência verbal. Isto se faz necessário devido à característica fundamental de exames de neuroimagem funcional: comparação entre dois (ou mais) "estados cognitivos" do cérebro. Essa comparação é feita por meio de métodos computacionais com técnicas estatísticas complexas para analisar as imagens - o que faz com que o resultado do estudo seja conhecido somente após algumas horas.

O princípio da RMf é a oxigenação sangüínea. ${ }^{3}$ Em áreas com maior atividade neuronal, há oferta de oxigênio maior que o consumo local. Isto causa um aumento da concentração regional de hemoglobina saturada de oxigênio (oxi-hemoglobina). Essa molécula tem propriedades magnéticas diferentes da hemoglobina não saturada (desoxi-hemoglobina). Assim, utilizando técnicas especiais (sequiências BOLD) podemos observar pequenas variações da intensidade do sinal devidas à ativação cerebral.

É possível apresentar estímulos visuais, auditivos, sensiti- vos e mesmo olfativos e gustativos. A principal vantagem é a possibilidade de repetir várias vezes cada estudo no mesmo paciente, já que não há radiação ionizante ou necessidade de injeção de contraste.

A realização do exame é feita de modo a obter imagens do cérebro durante a execução da atividade que se quer estudar e outras imagens controle, onde essa tarefa não é executada. Desta forma o indivíduo realiza uma série de atividades enquanto o aparelho adquire as imagens, as quais serão analisadas posteriormente. Exemplificando, suponha que o estudo seja para avaliar quais as áreas cerebrais se correlacionam com a tarefa de fluência verbal. Inicialmente, durante 30 segundos, o indivíduo observa letras apresentadas visualmente numa tela. A orientação é gerar palavras que se iniciem com a letra apresentada. Nos 30 segundos seguintes são apresentadas palavras, que devem ser simplesmente lidas (imagens controle). Essas tarefas são repetidas, num total de cinco ciclos, durante os quais são adquiridas cerca de cem imagens de todo o cérebro (uma a cada três segundos). Uma outra técnica - RMf relacionada a eventos - permite maior resolução temporal e flexibilidade, mas está além do escopo do presente artigo.

Após a análise, são mostradas as áreas que apresentaram aumento do sinal de RM no momento de geração das palavras em relação às imagens adquiridas durante o controle (leitura passiva). ${ }^{4}$ A Figura 2 mostra o resultado desse tipo de exemplo, onde áreas do lobo frontal esquerdo, da porção superior do lobo temporal e do lobo parietal deste lado mostram correlação com a tarefa de fluência verbal. Atualmente, as aplicações são principalmente em pesquisa. ${ }^{5}$ A RMf, potencialmente, poderá ser utilizada como dado adicional para planejamento cirúrgico ou para avaliar o impacto de determinado procedimento terapêutico no desempenho do paciente em determinada função cognitiva. ${ }^{6}$

\section{Conclusão}

A avaliação estrutural de transtornos psiquiátricos tem se beneficiado do avanço tecnológico. O grande volume de pesquisa em neuroimagem torna mais próxima a aplicação clínica desses achados.

\section{Referências}

1. Osborne AG. Diagnostic neuroradiology. $1^{\mathrm{a}}$ ed. St. Louis: Mosby; 1994.

2. Wright IC, Rabe-Hesketh S, Woodruff PW, David AS, Murray RM, Bullmore ET. Meta-analysis of regional brain volumes in schizophrenia. Am J Psychiatry 2000;157(1):16-25.

3. Ogawa S, Lee TM, Kay AR, Tank DW. Brain magnetic resonance imaging with contrast dependent on blood oxygenation. Proc Natl Acad Sci USA 1990;87:9868-72.
4. Brammer MJ, Bullmore ET, Simmos A, Williams SCR, Grasby PM, Howard RJ, et al. Generic brain activation mapping in fMRI: a nonparametric approach. Magn Reson Imaging 1997;15:763-70.

5. Shergill SS, Bullmore E, Simmons A, Murray R, McGuire P. Functional anatomy of auditory verbal imagery in schizophrenic patients with auditory hallucinations. Am J Psychiatry 2000;157(10):1691-3.

6. Glover GH, Herfkens RJ. Research directions in MR imaging [editorial]. Radiol 1998;207:289-95.

\section{Correspondência: Edson Amaro Júnior}

Division of Psychological Medicine, Institute of Psychiatry

De Crespigny Park, Denmark Hill, SE5 8AF - Londres, Reino Unido

E-mail: sphaeam@iop.kcl.ac.uk 
Rev Bras Psiquiatr 2001;23(Supl I):61-4

Aspectos básicos - p. 2-3

Figura 1 - Imagens de ressonância magnética

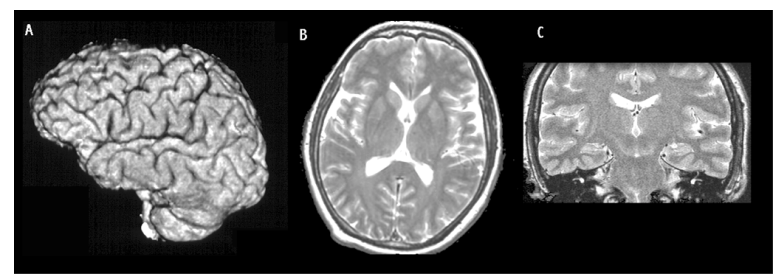

A) Reconstrução tridimensional, B) Axial T2 e C) Coronal T2.

Figura 2 - Imagem de ressonância magnética funcional - linguagem

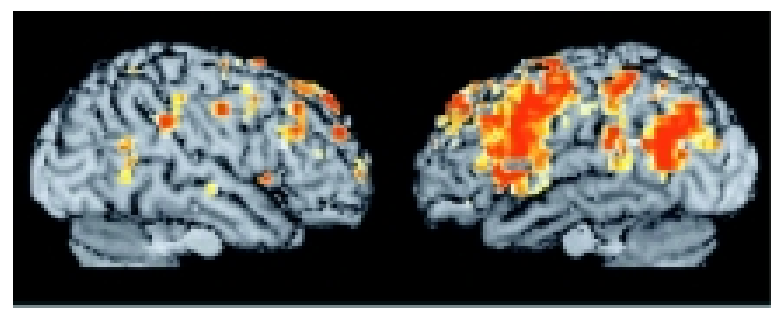

Ativação de áreas em córtex fronto-temporal durante tarefa de fluência verbal. 